\title{
DNA intercalator stimulates influenza transcription and virus replication
}

\author{
Olive TW Li, Leo LM Poon*
}

\begin{abstract}
Influenza A virus uses its host transcription machinery to facilitate viral RNA synthesis, an event that is associated with cellular RNA polymerase II (RNAPII). In this study, various RNAPII transcription inhibitors were used to investigate the effect of RNAPII phosphorylation status on viral RNA transcription. A low concentration of DNA intercalators, such as actinomycin D (ActD), was found to stimulate viral polymerase activity and virus replication. This effect was not observed in cells treated with RNAPII kinase inhibitors. In addition, the loss of RNAPII in infected cells was due to the shift of nonphosphorylated RNAPII (RNAPII ${ }_{a}$ ) to hyperphosphorylated RNAPII (RNAPII ${ }_{0}$ ).
\end{abstract}

\section{Introduction}

The C-terminal domain (CTD) of RNAPII is important for cellular mRNA transcription, and interacts with several post-transcriptional factors for RNA maturation and nuclear export. The phosphorylation status of CTD is known to be a critical regulatory checkpoint for RNAPII transcription [1]. The hyperphosphorylated (transcriptionally engaged) form of RNAPII is designated as RNAPII whereas its nonphosphorylated (transcriptionally inactive) form is designated as RNAPII . At the early stage of transcription, free RNAPII ${ }_{a}$ interacts with other general transcription factors on cellular DNA promoters to form a transcription pre-initiation complex, which is followed by transcription initiation [2]. The newly initiated RNAPII then proceeds to the promoter-proximal pause region, and the paused RNAPII $_{\mathrm{a}}$ is subsequently hyperphosphorylated, preferably on the serine 5 (Ser5) positions, by cyclindependent kinase (Cdk) 7. As transcription elongation proceeds, the serine 2 (Ser2) and Ser5 positions in the CTD of RNAPII are hyperphosphorylated by Cdk9 [3] and dephosphorylated by SCP1 [4], respectively. The Ser5phosphorylation helps to recruit enzymes to cap the nascent RNA transcript, whereas the Ser2-phosphorylation facilitates the conversion of RNAPII into a productive elongating form.

Influenza viral RNA synthesis is dependent on its host transcription machinery. Various RNAPII inhibitors such

\footnotetext{
* Correspondence: IImpoon@hkucc.hku.hk

State Key Laboratory for Emerging Infectious Diseases, Department of Microbiology and the Research Centre of Infection and Immunology, The University of Hong Kong, Hong Kong
}

as $\alpha$-amantin and actinomycin $\mathrm{D}$ (ActD) have been shown to inhibit influenza virus replication [5-7]. Chan et al. demonstrated that the influenza viral polymerase complex can inhibit RNAPII transcription elongation, but not initiation [8], a phenomenon that is similar to the transcriptional arrest of RNAPII. This transcriptional arrest may be related to direct interaction between vRNP and

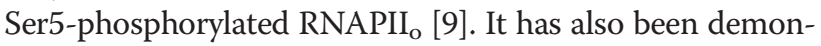
strated that a robust polymerase complex is more capable of binding to RNAPII ${ }_{o}$ [10]. Recently, influenza viral polymerase has been proposed to induce the direct degradation of RNAPII ${ }_{a}$ [11-13], thereby inhibiting host gene expression. The overall conclusion of these previous findings is that RNAPII plays a critical role in viral RNA transcription, although little is known about the mechanism responsible for RNAPII $_{a}$ disappearance during infection. Moreover, the role played by the post-translation modification of RNAPII in viral RNA synthesis is yet to be determined. In this study, we would like to determine the effect of various RNAPII inhibitors on influenza viral polymerase functions and virus replications. In particular, the inhibitors used in this study are known to inhibit RNAPII via different mechanisms and have different effects on the phosphorylation status of RNAPII. It is of our interest to use these chemicals to understand how the influenza virus can utilize RNAPII to facilitate viral RNA synthesis.

\section{Findings}

This study examined the effects of various RNAPII transcription inhibitors on viral RNA synthesis. A luciferasebased influenza viral polymerase reporter assay [10] was 
used to measure the viral polymerase activity in drugtreated cells. Transfected cells were first treated with different RNAPII inhibitors at six hours posttransfection and then tested for luciferase activity at 22 hours post-transfection (Figure 1). ActD, a DNA intercalator that is well-known to convert RNAII $\mathrm{a}_{\mathrm{a}}$ to RNAPII $_{\mathrm{o}}$ [14], was found to inhibit viral polymerase activity at high concentrations (Figure 1A). Strikingly, however, ActD at the low concentration range $(\sim 10 \mathrm{ng} / \mathrm{ml})$ was consistently found to stimulate viral polymerase activity by $50 \%$. This ActD activation effect was previously observed in genes containing an HIV-1 LTR sequence [15]. ActD at this low concentration range can increase the RNAPII ${ }_{o}$ population by creating temporary transcriptional obstacles for RNAPII ${ }_{o}[15,16]$, which suggests that the blockage of RNAPII ${ }_{o}$ transcription may facilitate viral gene expression. This activation effect was further confirmed by the use of another DNA intercalator, ethidium bromide (EtBr), to induce the stalling of RNAPII ${ }_{o}$. As shown in Figure 1B, a two-fold increase in viral polymerase activity was observed in cells treated with
$2.5 \mu \mathrm{g} / \mathrm{ml}$ of EtBr. In contrast, Cdk inhibitors 5,6-dichlorobenzimidazole riboside (DRB) and 1-(5'-isoquinolinesulfonyl)-2-methylpiperazine (H7), which can inhibit the phosphorylation of RNAPII ${ }_{a}$, failed to exhibit similar stimulating effects on such activity (Figures $1 \mathrm{C}$ and 1D). Using a GFP expression plasmid under the control of a CMV promoter as a control, it was then confirmed that these DNA intercalators in the concentrations under investigation cannot enhance cellular RNAPII transcription [15] (Additional File 1). In short, these results suggest that influenza viral polymerase may require $\mathrm{RNAPII}_{\mathrm{o}}$, or the formation of RNAPII ${ }_{o}$, for efficient viral transcription.

To test whether the unexpected enhancement effect of ActD on viral polymerase has any impact on virus replication, MDCK cells were treated with various concentrations of ActD immediately after viral infection. Briefly, MDCK cells were infected with A/WSN/33 for one hour. In order to observe the maximal effect of this drug on a single round of virus replication, cells were super-infected with the virus at an MOI of 10 . The uninfected virus in the inoculums was inactivated by a
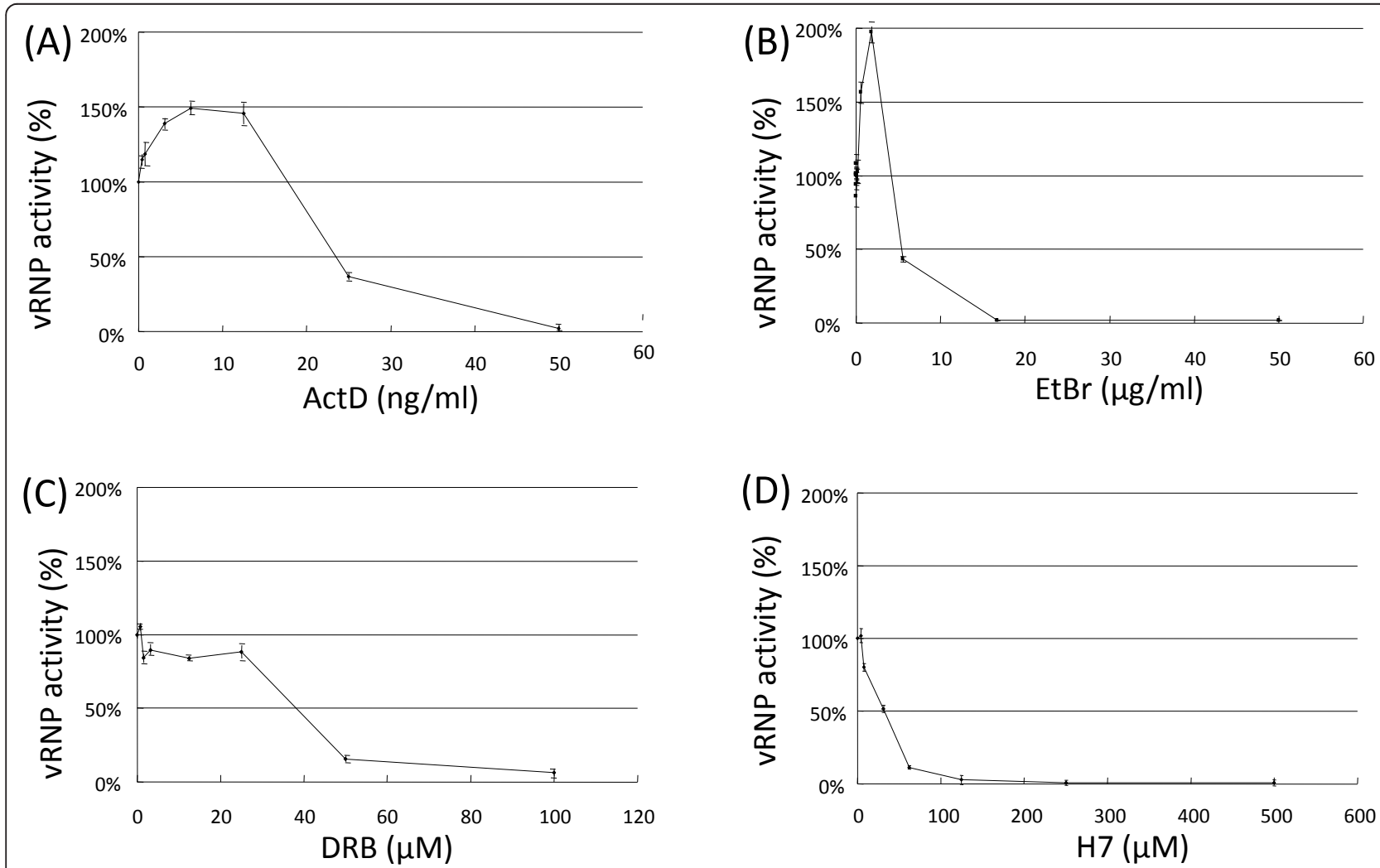

Figure 1 Effects of RNAPII transcription inhibitors on influenza viral polymerase activity. 293T cells were transfected with A/WSN/33 PB2, PB1, PA and NP protein expression plasmids and a pPoll Luc-RT RNA expression plasmid, as described previously [10]. The transfected cells were then washed and replenished with media containing various concentrations of ActD (A), DRB (B), H7 (C) or EtBr (D) at six hours post-transfection The luciferase activity of the drug-treated cells was measured with a luminometer (Victor3, PerkinElmer) using a Steady-Glo luciferase reagent (Promega) at 22 hours post-transfection. The luciferase activity of the mock-treated cells was taken as 100\% polymerase activity. Data \pm SE were obtained from the triplicate experiments. 
short acidic buffer wash after infection. The amount of progeny viral particles generated from the treated cells at six (i.e. $<1$ virus replication) and eight (i.e. $\sim 1$ virus replication cycle) hours post-infection was determined. As shown in Figure 2A, influenza virus replication can be abolished by treating infected cells with $1 \mu \mathrm{g} / \mathrm{ml}$ of ActD, as expected [17]. Unlike the results obtained from the transfected 293T cells used in the aforementioned luciferase assay, MDCK cells treated with $100 \mathrm{ng} / \mathrm{ml}$ of ActD can still support virus replication. These observations suggested these cell lines might have different tolerances to the drug. Nonetheless, a low concentration of
ActD was also found to enhance virus replication significantly $(\mathrm{p}<0.05)$. For example, the viral titre from cells treated with $1 \mathrm{ng} / \mathrm{ml}$ of ActD at 8 hours post-infection was found to be 2.2-fold higher than that of the mock control. This stimulating effect, however, was not observed in cells treated with DRB (Figure 2B). These results indicate that different RNAPII inhibitors may have different effects on virus replication and that these differential effects may be due to different phosphorylation statuses of CTD (see below).

ActD intercalates DNA, and inhibits transcription elongation by immobilizing the RNAIIP $_{o}$ on DNA

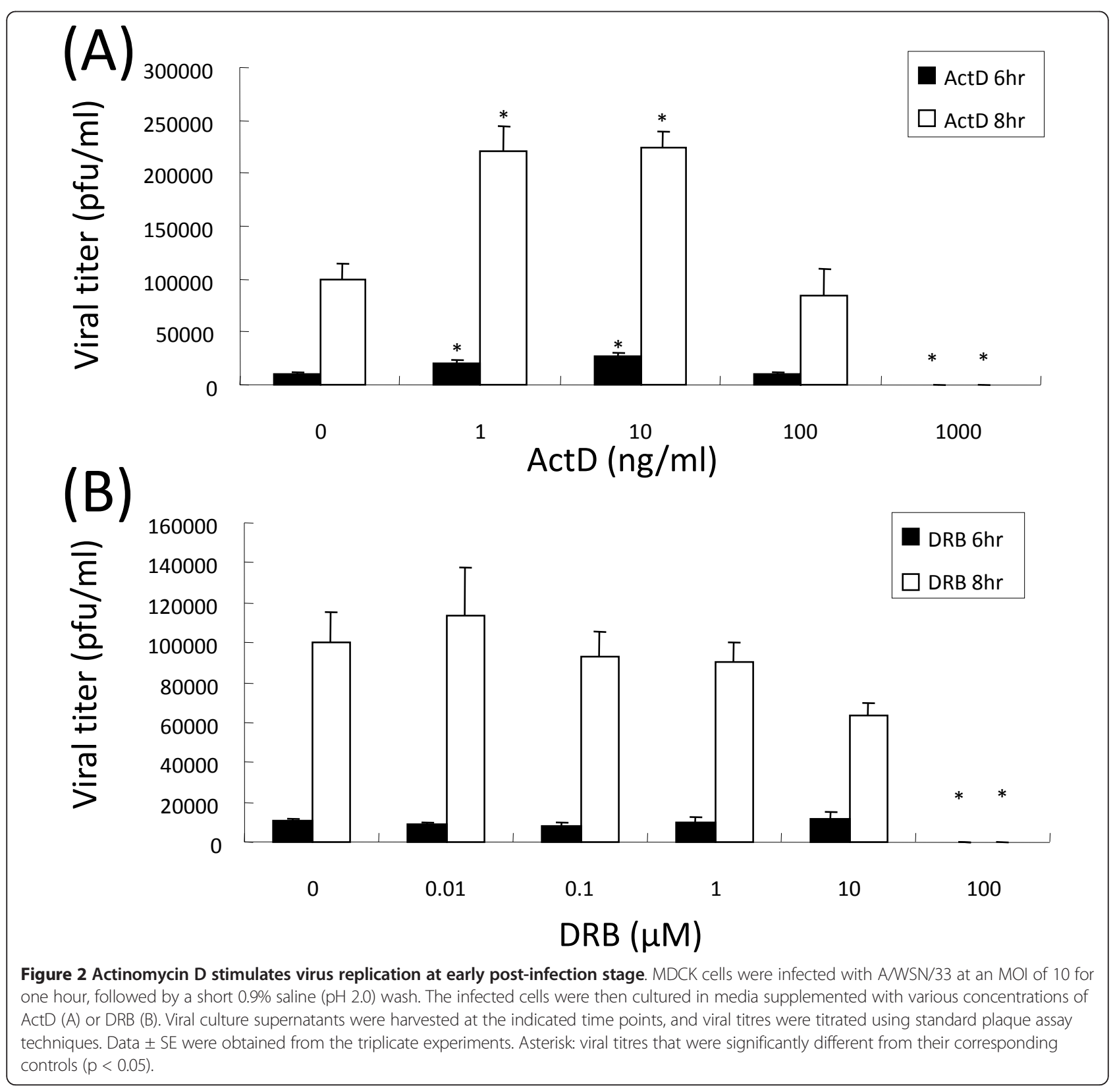




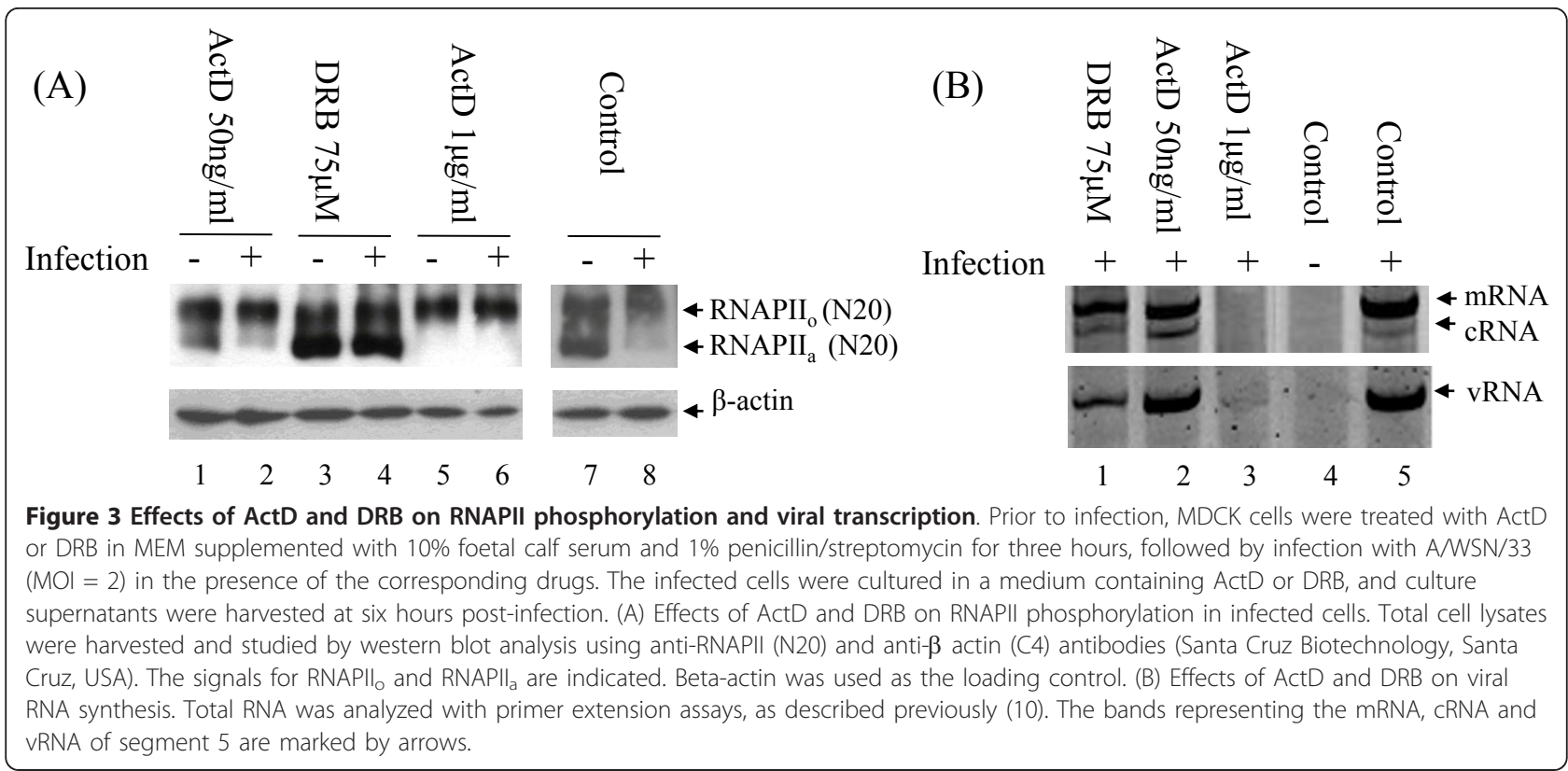

templates [18]. DRB, in contrast, is a Cdk inhibitor that inhibits the phosphorylation of RNAPII ${ }_{a}$ [19]. We therefore took advantage of the distinct inhibitory mechanisms of these two chemicals to investigate the disappearance of RNAPII $_{a}$ in influenza virus-infected cells. MDCK cells were pre-incubated with ActD or $\mathrm{DRB}$ at a predetermined concentration known to have prominent change on CTD phosphorylation in the Western blot analyses (Figure 3A, lanes 1-4), but without severely affecting the viral RNA transcription and replication in the subsequent viral infection (Figure 3B, lanes 2 and 1). As shown in Figure 3A (lane 8 ), influenza viral infection promoted the disappearance of RNAPII ${ }_{a}$ in the untreated cells as described in previous investigations $[10,11,13]$. Cells treated with 1 $\mu \mathrm{g} / \mathrm{ml}$ of ActD had a complete conversion of RNAPII ${ }_{a}$

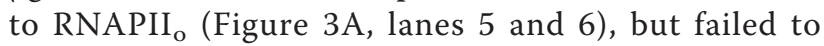
support viral RNA synthesis ( $3 \mathrm{~B}$, lane 3). Cells treated with $50 \mathrm{ng} / \mathrm{ml}$ of ActD had reduced levels of RNAPII (Figure 3A, lane 1) and remained able to support viral RNA synthesis (Figure 3B, lane 2). It should be noted that viral infection is still capable of inducing the disappearance RNAPII ${ }_{a}$ at this concentration of ActD (Figure 3A; compare lanes 1 and 2), suggesting that the phophorylation of $\mathrm{RNAPII}_{\mathrm{a}}$ is essential for virus replication. On the other hand, viral transcription and replication products were detected in the infected cells treated with $75 \mu \mathrm{M}$ of DRB (Figure 3B, lane 1), although the treatment was found to inhibit the disappearance of RNAPII induced by the infection (Figure 3A, lane 4). Previous co-immunoprecitation work has demonstrated that viral polymerase interacts specifically with Ser5-phosphorylated, but not Ser2- phophorylated, RNAPII ${ }_{\mathrm{o}}$ [9]. Hence, the results of both the current and previous studies suggest that viral polymerase may need to recruit and arrest newly formed RNAPII (i.e., Ser-5-phophorylated RNAPII), but not the actively elongating form of RNAPII Ser-2-phophorylated RNAPII), for viral RNA transcription.

\section{Conclusion}

Influenza A virus infection results in a significant loss of transcriptionally inactive RNAPII (RNAPII ${ }_{\mathrm{a}}$ ) [11-13]. However, as influenza polymerase requires capped primers snatched from the host nuclear RNA for its viral RNA transcription [20-22], a direct induction of RNA$\mathrm{PII}_{\mathrm{a}}$ degradation via the viral polymerase may not favour such a transcription. In this study, it has been demonstrated here that the disappearance of RNAPII ${ }_{a}$ is

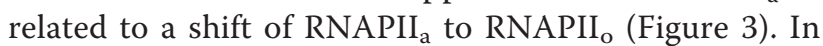
addition, this conversion of RNAPII ${ }_{a}$ to RNAPII $_{o}$ is found to be important to viral RNA synthesis, which suggests that newly synthesized RNAPII $_{o}$ may be a critical determinant of viral transcription. RNAPII can be subjected to various post-translational modifications [1]. Further investigation of the post-translational modification of RNAPII in influenza virus-infected cells may help us to better understand the transcription and replication of influenza viruses.

\section{Additional material}

Additional file 1: Effects of EtBr on GFP expression. 293T cells were transfected with GFP expressing plasmid under the control of a CMV promoter. The transfected cells were then washed and replenished with 
media containing various concentrations of $\mathrm{EtBr}$ at six hours posttransfection. The GFP signal was measured with a luminometer (Victor3, PerkinElmer) at 22 hours post-transfection. The GFP signal of the mocktreated cells was taken as $100 \%$ polymerase activity. Data \pm SE were obtained from the triplicate experiments.

\section{Acknowledgements}

This project is supported by National Institutes of Health (NIAID contract HHSN266200700005C, LLM), Research Grant Council of Hong Kong (HKU 7530/06M, LLM), Area of Excellence Scheme of the University Grants Committee (Grant AoE/M-12/06). We thank George Brownlee for plasmids, Ervin Fodor and Hui-Ling Yen for critical comments.

\section{Authors' contributions}

OTWL designed the study and conducted the experiments. LLMP supervised the project. Both OTWL and LLMP analysed the data, wrote the manuscript and approved the final version of the manuscript.

\section{Competing interests}

The authors declare that they have no competing interests.

Received: 1 February 2011 Accepted: 15 March 2011

Published: 15 March 2011

\section{References}

1. Egloff S, Murphy S: Cracking the RNA polymerase II CTD code. Trends Genet 2008, 24:280-288.

2. Fuda NJ, Ardehali MB, Lis JT: Defining mechanisms that regulate RNA polymerase II transcription in vivo. Nature 2009, 461:186-192.

3. Palancade B, Bensaude O: Investigating RNA polymerase II carboxylterminal domain (CTD) phosphorylation. Eur J Biochem 2003, 270:3859-3870.

4. Zhang Y, Kim Y, Genoud N, Gao J, Kelly JW, Pfaff SL, Gill GN, Dixon JE, Noel JP: Determinants for dephosphorylation of the RNA polymerase II C-terminal domain by Scp1. Mol Cell 2006, 24:759-770.

5. Kurokawa M, Ochiai H, Nakajima K, Niwayama S: Inhibitory effect of protein kinase $C$ inhibitor on the replication of influenza type $A$ virus. J Gen Virol 1990, 71(Pt 9):2149-2155.

6. Minor PD, Dimmock NJ: Selective inhibition of influenza virus protein synthesis by inhibitors of DNA function. Virology 1977, 78:393-406.

7. Nguyen VT, Giannoni F, Dubois MF, Seo SJ, Vigneron M, Kedinger C, Bensaude O: In vivo degradation of RNA polymerase II largest subunit triggered by alpha-amanitin. Nucleic Acids Res 1996, 24:2924-2929.

8. Chan AY, Vreede FT, Smith M, Engelhardt OG, Fodor E: Influenza virus inhibits RNA polymerase II elongation. Virology 2006, 351:210-217.

9. Engelhardt $O G$, Smith $M$, Fodor E: Association of the influenza $A$ virus RNA-dependent RNA polymerase with cellular RNA polymerase II. J Virol 2005, 79:5812-5818.

10. Li OT, Chan MC, Leung CS, Chan RW, Guan Y, Nicholls JM, Poon LL: Full factorial analysis of mammalian and avian influenza polymerase subunits suggests a role of an efficient polymerase for virus adaptation. PLoS One 2009, 4:e5658.

11. Rodriguez A, Perez-Gonzalez A, Nieto A: Influenza virus infection causes specific degradation of the largest subunit of cellular RNA polymerase II. J Virol 2007, 81:5315-5324.

12. Rodriguez A, Perez-Gonzalez A, Hossain MJ, Chen LM, Rolling T, PerezBrena $P$, Donis R, Kochs $G$, Nieto A: Attenuated strains of influenza A viruses do not induce degradation of RNA polymerase II. J Virol 2009, 83:11166-11174.

13. Vreede FT, Chan AY, Sharps J, Fodor E: Mechanisms and functional implications of the degradation of host RNA polymerase II in influenza virus infected cells. Virology 2010, 396:125-134.

14. Bensaude O, Bonnet F, Casse C, Dubois MF, Nguyen VT, Palancade B: Regulated phosphorylation of the RNA polymerase II C-terminal domain (CTD). Biochem Cell Biol 1999, 77:249-255.

15. Casse C, Giannoni F, Nguyen VT, Dubois MF, Bensaude O: The transcriptional inhibitors, actinomycin $D$ and alpha-amanitin, activate the HIV-1 promoter and favor phosphorylation of the RNA polymerase II C-terminal domain. J Biol Chem 1999, 274:16097-16106.

16. Fromaget M, Cook PR: Photobleaching reveals complex effects of inhibitors on transcribing RNA polymerase II in living cells. Exp Cell Res 2007, 313:3026-3033.

17. Mark GE, Taylor JM, Broni B, Krug RM: Nuclear accumulation of influenza viral RNA transcripts and the effects of cycloheximide, actinomycin D, and alpha-amanitin. J Virol 1979, 29:744-752.

18. Kimura H, Sugaya K, Cook PR: The transcription cycle of RNA polymerase II in living cells. J Cell Biol 2002, 159:777-782.

19. Dubois MF, Nguyen VT, Bellier S, Bensaude $\mathrm{O}$ : Inhibitors of transcription such as 5,6-dichloro-1-beta-D-ribofuranosylbenzimidazole and isoquinoline sulfonamide derivatives $(\mathrm{H}-8$ and $\mathrm{H}-7)$ promote dephosphorylation of the carboxyl-terminal domain of RNA polymerase II largest subunit. J Biol Chem 1994, 269:13331-13336.

20. Bouloy M, Morgan MA, Shatkin AJ, Krug RM: Cap and internal nucleotides of reovirus mRNA primers are incorporated into influenza viral complementary RNA during transcription in vitro. J Virol 1979, 32:895-904.

21. Plotch SJ, Bouloy M, Krug RM: Transfer of 5 '-terminal cap of globin mRNA to influenza viral complementary RNA during transcription in vitro. Proc Natl Acad Sci USA 1979, 76:1618-1622.

22. Plotch SJ, Tomasz J, Krug RM: Absence of detectable capping and methylating enzymes in influenza virions. J Virol 1978, 28:75-83.

\section{doi:10.1186/1743-422X-8-120}

Cite this article as: Li and Poon: DNA intercalator stimulates influenza transcription and virus replication. Virology Journal 2011 8:120.

\section{Submit your next manuscript to BioMed Central and take full advantage of:}

- Convenient online submission

- Thorough peer review

- No space constraints or color figure charges

- Immediate publication on acceptance

- Inclusion in PubMed, CAS, Scopus and Google Scholar

- Research which is freely available for redistribution

Submit your manuscript at www.biomedcentral.com/submit
Biomed Central 